\title{
Improvement of the Torsional Properties of Drawn High Carbon Steel Wire by the Control of Pearlitic Microstructure
}

\author{
Yutaka KANETSUKI,1) Yo HIRAI ${ }^{2)}$ and Rikuo OGAWA ${ }^{3)}$
}

1) Iron and Steel Research Laboratories, Kobe Steel, Ltd., Wakinohama-cho, Chuo-ku, Kobe, Hyogo-ken, 651 Japan.

2) KOBELCO Research Institute, Inc., Wakinohama-cho, Chuo-ku, Kobe, Hyogo-ken, 651 Japan. Section, Kobe Steel, Ltd., Wakinohama-cho, Chuo-ku, Kobe, Hyogo-ken, 651 Japan.

3) Superconducting and Cryogenic Technology

(Received on November 15, 1988; accepted in the final form on April 14, 1989)

\begin{abstract}
An investigation was made on the diameter dependence of the critical drawing strain for the delamination of drawn high carbon steel wires, in comparison with the effect of a new patenting method. The new method, which was designed to retard pearlite transformation with the aid of high pressure, made it possible to obtain thick rods transformed at the nose temperature as the thin rod patented conventionally. This method proved that the critical drawing strain for delamination did improve. Texture measurement showed the development of $\{110\}\langle 110\rangle$ and $\{110\}\langle 114\rangle$ cylindrical textures, and the deck of cards deformation mode was observed frequently in the wires patented by the new method.

The relation between the texture change and the orientation relationship of pearlite is discussed.
\end{abstract}

KEY WORDS: pearlite; high pressure; patenting; cylindrical texture; delamination.

\section{Introduction}

In the previous report ${ }^{11}$ studies on the behavior of delamination were reported, which revealed that delamination is a phenomenon characteristic of drawn wire, and is caused by the cylindrical texture formed by drawing. The texture formed by drawing was not the ideal $\langle 110\rangle$ fiber texture which is known generally as wire texture, but a cylindrical texture, where a specific crystallographic plane is oriented parallel to the wire surface, and the crystal orientation of the surface and the interior layers of the wire are different. Delamination, caused by the drawing process as stated above, interferes with the strengthening of steel wire. Furthermore, delamination is considered to have a close relation with pearlitic microstructure in view of the fact that the critical drawing strain with delamination depends on the as-patented wire rod diameter.

In the patenting process, the larger the wire rod diameter, the more difficult is the quenching for transformation of the core with nose temperature. Isothermal transformation can be achieved in wire rods smaller than $4 \mathrm{~mm}$. Consequently, the pearlitic lamellar spacing becomes increasingly more coarse from the surface toward the core, in thick wire rods.

In this study, the effect of the pearlitic microstructure on delamination and on the formation of texture was investigated, using the new patenting method by means of a high pressure apparatus. This new method has the advantage of reducing the mass effect of heat treatment, similar to the effect of the addition of alloying elements on hardenability. In the following sections, a continuous cooling transformation (CCT) diagram under high pressure is analyzed and the new patenting method is described in detail. By this new method, only mass effects can be reduced in contrast to the effect of alloying elements, and consequently the change in the mechanical properties of wire should be attributed to changes in the pearlitic microstructure such as lamellar spacing and crystallographic properties.

\section{Experimental Procedures}

\subsection{Material}

The chemical composition of the high carbon steel used in this study was as follows: $0.78 \% \mathrm{C}, 0.28 \% \mathrm{Si}$, $0.58 \% \mathrm{Mn}, 0.022 \% \mathrm{P}, 0.023 \% \mathrm{~S}, 0.02 \% \mathrm{Cu}, 0.03 \% \mathrm{Cr}^{11}$ The wire rods with diameter of 8.6 and $12.6 \mathrm{~mm}$ were prepared by machining of hot forged blanks. Before cold drawing, the wire rod was patented by the new method. The conventional method using a tin bath at a temperature of $550^{\circ} \mathrm{G}$ was also used for comparison.

\subsection{New Patenting Method}

The new patenting method is shown schematically in Fig. 1. This method was designed so that hydrostatic pressure could be applied to the wire rods during the supercooling state by means of hot dies. In order for rapid cooling and holding of wire rod at nose temperature to take place, the dies were heated in advance to the nose temperature of $550^{\circ} \mathrm{G}$. The measured cooling velocity of the wire rod with this method was almost the same as that with the conventional method. Consequently, the difference between the two methods in the influence of the cooling velocity was negligible. The wire rod was austenitized at the temperature of $950^{\circ} \mathrm{C}$ and inserted into the hole 
(A)

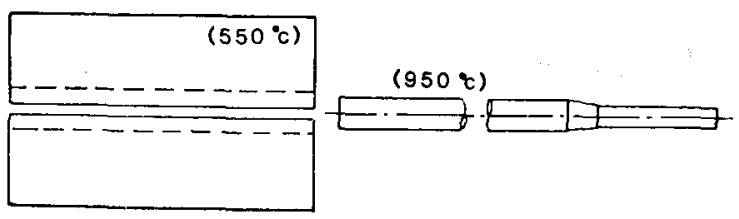

(B)

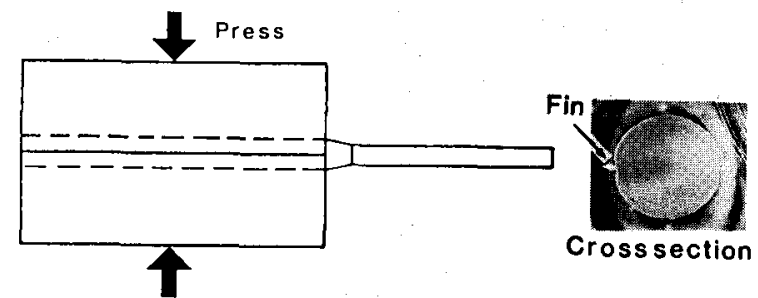

(c)
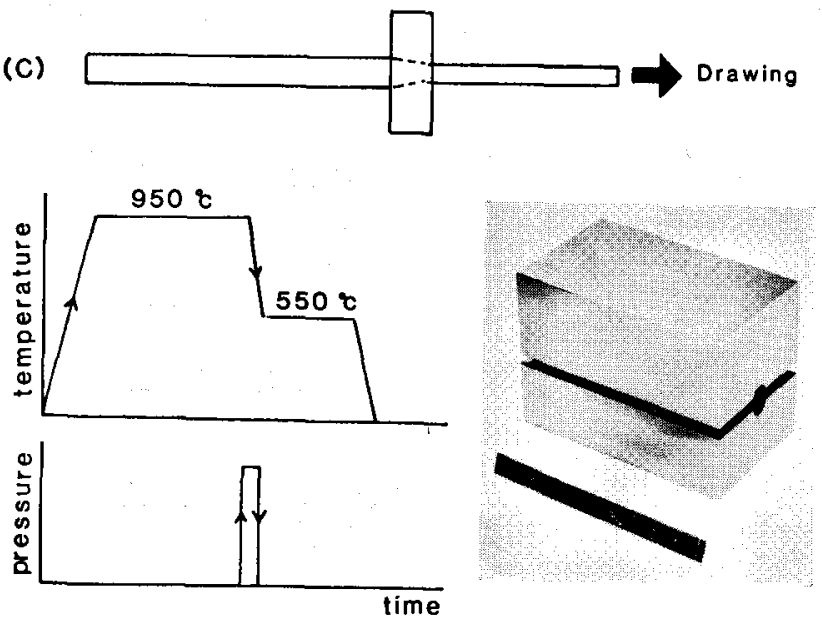

(A), (B): The progressive operation of the new patenting method

Photographs: The dies used (lower) and the cross section of the wire rod produced by this method

Fig. 1. Schematic illustration of the new patenting method.

between two dies, which were initially set $5 \mathrm{~mm}$ apart so that the wire rod could be inserted. The diameter of the hole was $0.6 \mathrm{~mm}$ smaller than that of the wire rod to assure close contact. The dies with the wire rod inserted in the hole were then set in the press. When the wire rods were cooled to the die temperature by compression of the dies, the press load was quickly reduced so as to enable pearlite reaction under atmospheric pressure and to avoid other effects of pressure on transformation, such as reduced transformation velocity, a decrease of the eutectoid carbon content, and a morphology change. ${ }^{2)}$

The length of the dies was $10 \mathrm{~cm}$, which was long enough to apply hydrostatic pressure to the wire rod with the aid of frictional stress between dies and wire rod. However, it is impossible to measure the actual pressure during operation of the new method. Therefore the pressure was estimated by the calculation of the stress. To evaluate the calculated pressure, the GGT diagram under hydrostatic pressure was measured.

Fig. 2 shows the cubic anvil-type high pressure apparatus. The specimens were heated by a carbon heater to a temperature of $950^{\circ} \mathrm{C}$, and then cooled by decreasing the electric power of the heater. The

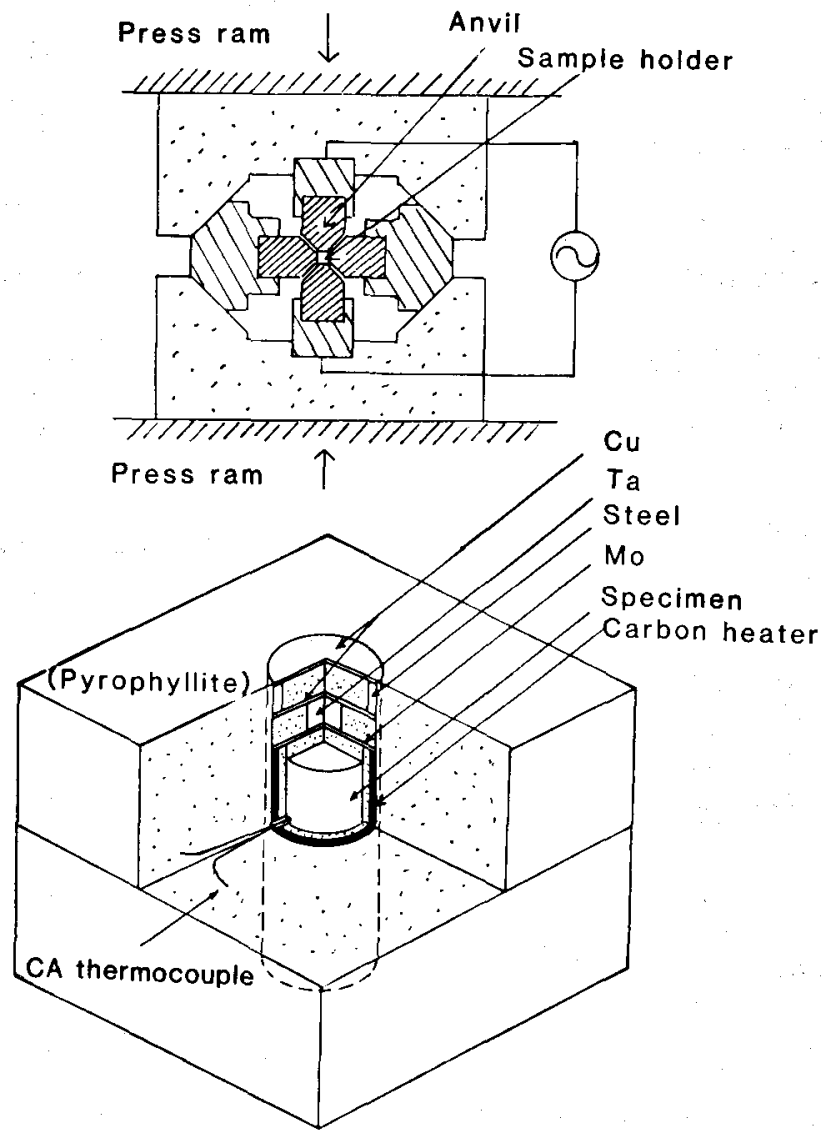

Fig. 2. Schematic illustration of the cubic anvil type hydrostatic pressure apparatus and the arrangement of a sample assembly.

starts of transformation were ascertained by using a $\mathrm{C}-\mathrm{A}$ thermocouple to measure the temperature recalescence due to the transformation.

\subsection{Drawing and Mechanical Testing}

Drawing was performed by a pass schedule with about a $15 \%$ reduction of area per pass, with the usual dies. The lubricant used was Molykote \#321, and the drawing velocity was $8 \mathrm{~m} / \mathrm{min}$. Before drawing, the fin shown in Fig. 1 was removed and a slight change in circular cross section was corrected by machining. The fin was formed due to a difference in the diameter between a rod and the hole in the dies, and acted as a pressure seal.

The mechanical properties of the drawn wires were evaluated by tension and torsion tests with samples obtained at each pass. A torsion test was carried out by loading $1 \%$ of the breaking load at one end and twisting at a torsional speed of 1 r.p.m. The point of drawing strain critical for delamination was determined by torsion testing; that is, the critical drawing strain was determined as the drawing strain above which a sudden torque drop caused by the splitting of the wire in a lengthwise direction was observed during a torsion test. (This behavior was described in detail in the previous report. ${ }^{11}$ ) Finally, the results obtained by the two methods were compared.

\subsection{Texture Measurement}

The normal pole figures were measured by means 
of the Schulz reflection method using Co- $K \alpha$ radiation. The flat specimens for pole figure measurement were prepared from a thin cylinder machined by drilling the core out of the wire which had been drawn from a $12 \mathrm{~mm}$ wire rod to $4 \mathrm{~mm}$ wire (see previous report $\left.{ }^{11}\right)$.

The texture development of the thin wire rod patented conventionally was measured on the basis of the relative pole intensity along the wire axis with Mo- $K \alpha$ radiation from the cross sections of the wire axis. The pole intensity of the deformed state was compared with the as-heat-treated state. With the result of the present experiment on normal pole figure measurement, the (114) reflection as well as the (110) reflection was selected. The (114) reflection was superimposed on the (330) reflection, so that the intensity of the (114) reflection was estimated by subtracting the (330) intensity, which could be calculated by using the theoretical ratio between the (114) and the (330) reflections of the initial state and the measured ratio of the (110) intensity between the drawn wire and the undeformed wire rod. ${ }^{3)}$ The results obtained from thick wire rod were compared on the basis for discussion of wire rod diameter dependence observed in the conventional method.

\section{Results}

\subsection{Dependence of the Critical Drazeing Strain on the} Diameter of the Wire Rods Patented by the Conventional Method

First, a preliminary investigation on the delamination of conventionally patented wire rods will be presented.

Fig. 3 shows the dependence of the critical drawing strain on the initial wire rod diameter in the case of the conventional patenting method. The influence of the bath temperature in the case of $4 \mathrm{~mm}$ wire rod is given in the figure. The critical drawing strain de-

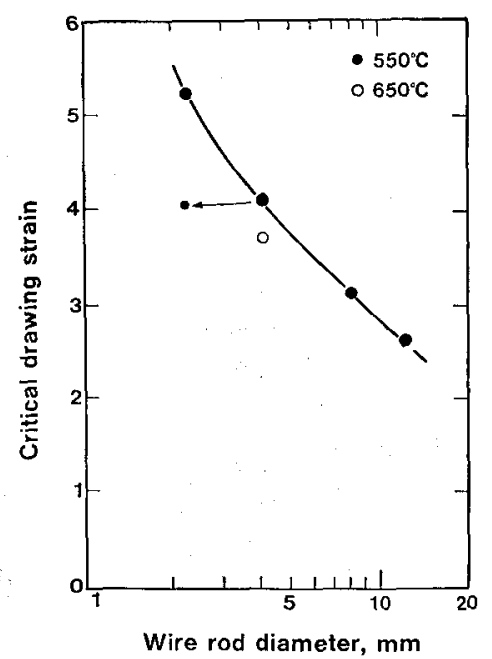

Fig. 3. Relation between critical drawing strain for delamination and the wire rod diameter as-patented. Arrow indicates the change in critical drawing strain caused by reducing the diameter of wire rod by chemical polishing. creased as the bath temperature increased. Fig. 3 shows, as indicated by arrow, the change in critical drawing strain when conventionally patented wire rod of $4 \mathrm{~mm}$ diameter was chemically polished to $2 \mathrm{~mm}$ diameter. When the rod was polished from 4 to $2 \mathrm{~mm}$ diameter, the critical drawing strain did not change. These two results indicate that delamination is affected mainly by the pearlitic microstructure at the surface layer of the wire rod. Furthermore, it is considered that the pearlitic microstructure of the surface of the wire rod, transformed near the nose temperature, has a significant influence on delamination, compared with the results for the $2 \mathrm{~mm}$ wire rods, as shown in Fig. 3. To confirm the above suggestion obtained by this preliminary examination, the new patenting method was applied to thick wire rod with diameters of 8 and $12 \mathrm{~mm}$. This made it possible to investigate the effect of the pearlitic microstructure directly.

\subsection{Critical Drawing Strain of Wire Rod Patented by the New Method}

\subsubsection{Pearlitic Transformation by the New Method}

Fig. 4 shows the typical cooling curves of the center of the $8 \mathrm{~mm}$ diameter wire rod which was measured by a spot-welded P-R thermocouple. These cooling curves showed that when the press load was increased to $132 \mathrm{t}$ the transformation was retarded but that the reduction of the load removed this effect, and so, the transformation occurred at $550^{\circ} \mathrm{C}$. The wire rod for drawing was treated using dies with holes 8 and 12 $\mathrm{mm}$ in diameter. A load of $300 \mathrm{t}$ was applied, enough to obtain a homogeneous hardness distribution throughout the cross section of the wire rod.

Fig. 5 shows the pearlitic microstructure observed at the center of the wire rod. The $12 \mathrm{~mm}$ wire rod patented by the new method (Fig. 5(B)) shows very fine lamellar spacing in comparison with the rod patented by the conventional method (Fig. 5(A)). This fine lamellar structure is identical to that of the thin wire rod patented by the conventional method, as shown in Fig. 5(C). The transmission electron microscopy image in Fig. 5(D) shows that with the new method there is no other change in microstructure except for reduced lamellar spacing. Thus, these figures show that the microstructure obtained by the new method was identical to that of the thin wire rod patented by the conventional method.

\subsubsection{Mechanical Properties of the Wires Patented by the New Method}

The mechanical properties after drawing are shown in Fig. 6, and compared with those which resulted with the conventional method. In this figure, the critical drawing strain with delamination is plotted on the horizontal axis. The strength and the work hardening behavior were not altered, but the reduction of area at drawing strains higher than 1.5, and especially the critical drawing strain, were improved. As with pearlite microstructure, the mechanical properties resulting from use of the new patenting method coincided with those observed when patenting was 

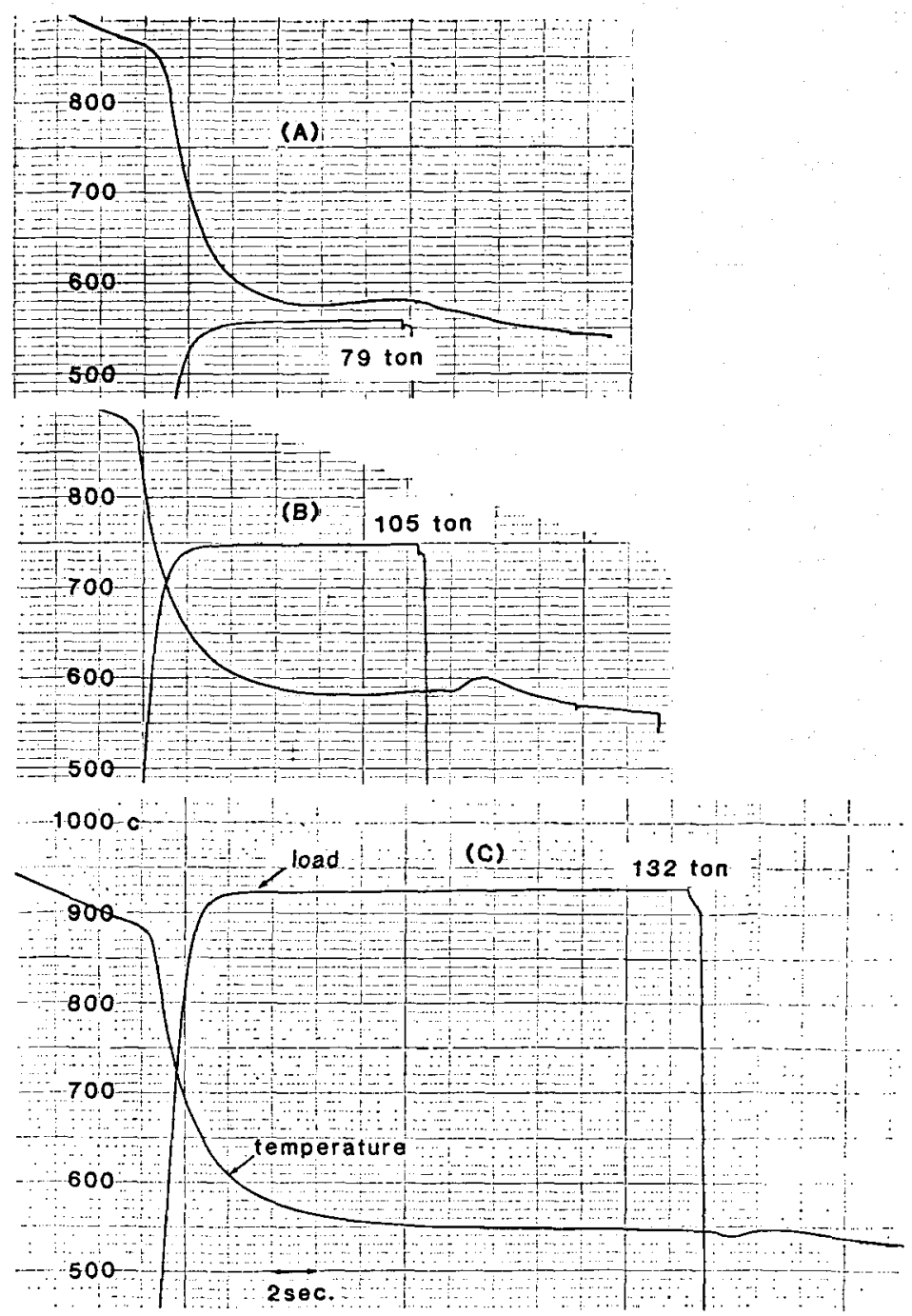

Fig. 4. Loading curves and cooling curves measured at the center of the $8 \mathrm{~mm}$ wire rods during the operation of the new patenting method.

done by the conventional method to wire rod of reduced diameters (see previous report ${ }^{13}$ ).

\subsection{Improvement of the Critical Drawing Strain by the New Method}

Fig. 7 shows the CCT diagram, under hydrostatic pressure, of high carbon steel used in this study. The nose of the pearlite transformation shifts to a longer time with an increase in hydrostatic pressure. The arrows in Fig. 7 indicate the observed cooling curves of the center of the wire rods patented by the new method, which were identical to those resulting with the conventional method. On the basis of these CCT diagrams, the most efficient pressure for the homogeneous patenting of wire rod with a diameter of 12 $\mathrm{mm}$ was predicted to be about $1 \mathrm{GPa}$.

In Fig. 8, the relation between the critical drawing strain and the normal stress applied by the new method for wire rod with a diameter of $12 \mathrm{~mm}$ is shown. Normal stress means the load per unit area which is perpendicular to the loading direction. In comparison with the critical drawing strain resulting with the conventional method, improvement in the critical

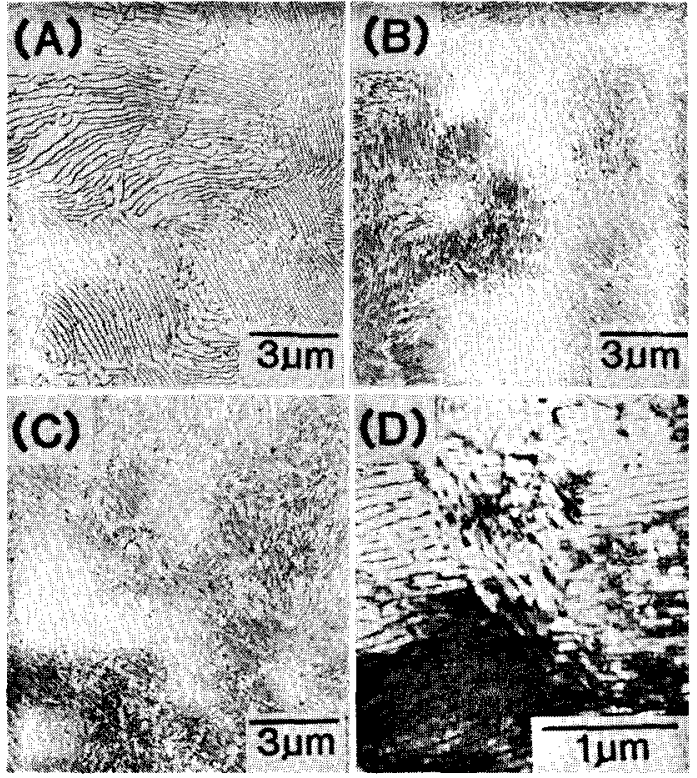

(A) $12 \mathrm{~mm}$ wire rod patented by the conventional method

(B) $12 \mathrm{~mm}$ wire rod patented by the new method

(C) $4 \mathrm{~mm}$ wire rod patented by the conventional method

(D) Transmission electron micrograph of specimen (B)

Fig. 5. Pearlitic microstructure of the wire rod patented by the conventional and the new methods.

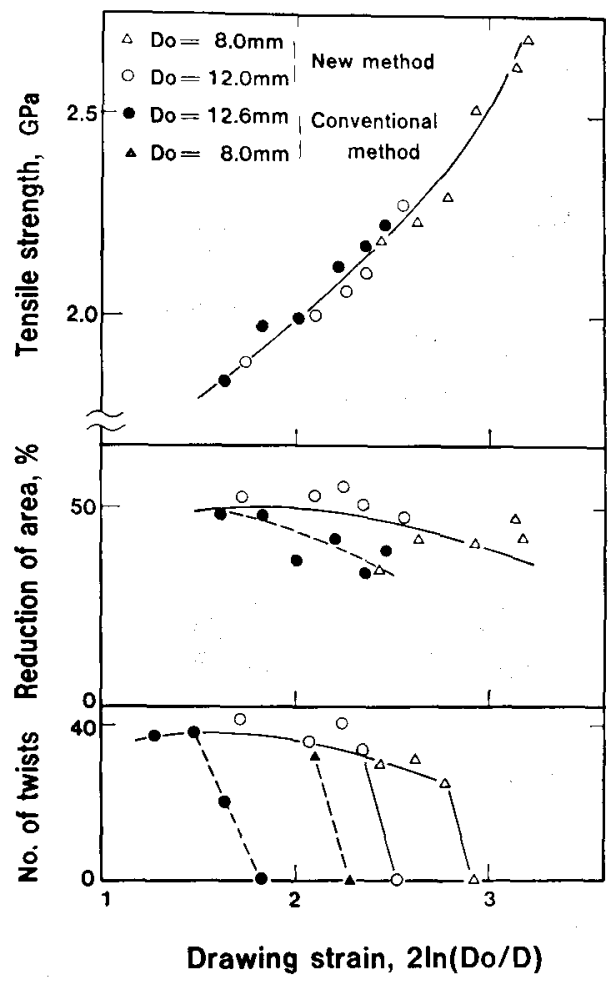

Fig. 6. Mechanical properties of drawn wires patented by the conventional and the new methods.

drawing strain was observed at a pressure above $1 \mathrm{GPa}$ when the new method was used. In other words, in Fig. 8, 1.3 GPa was the cross point of the 


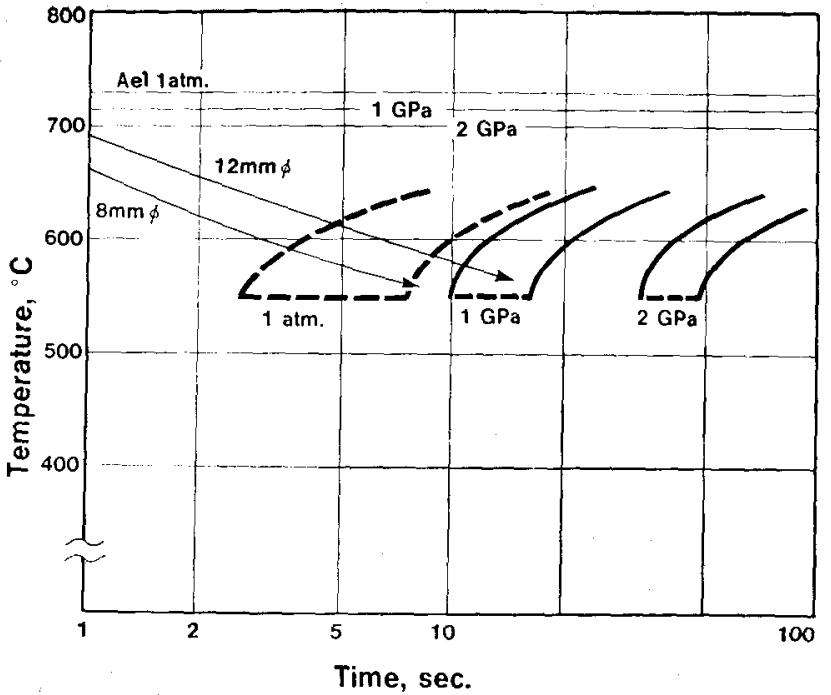

Fig. 7. CCT diagram of eutectoid steel under high pressure. Arrows indicate the measured cooling curves during the operation of the new method.

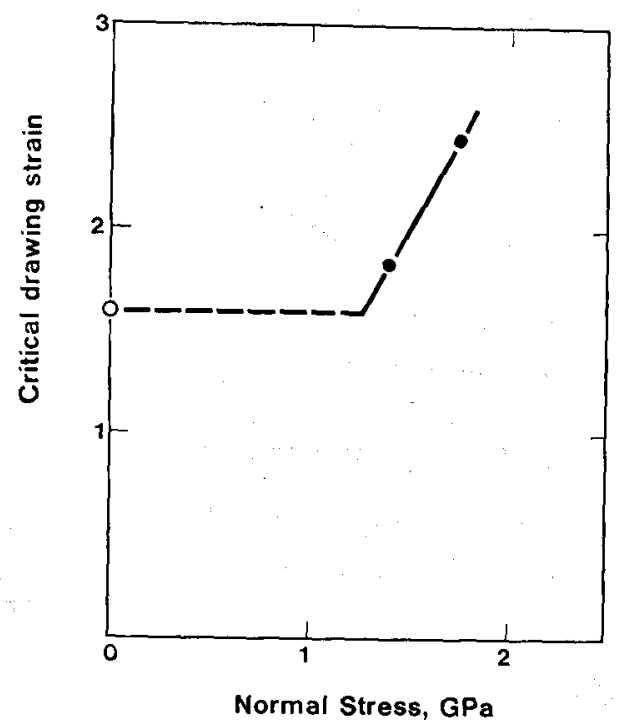

$O$ : The critical drawing strain with the use of the conventional method

Fig. 8. Relation between the critical drawing strain for delamination and the normal stress with the use of the new patenting method.

solid line and the broken line which indicates the critical drawing strain under atmospheric pressure. This value roughly corresponds with the pressure predicted from the CGT diagram. Above $1 \mathrm{GPa}$, the critical drawing strain increases with an increase in pressure. This fact indicates that the factor affecting delamination would be a change of property which occurs predominantly at the nose temperature, although a change in hardness due to decreasing of lamellar spacing was no longer observed at the nose temperature.

\subsection{Textures of Drawen Wires and the Change in Micro- structure}

Fig. 9 shows the (110) pole figures formed by drawing. The specimen was made from $4 \mathrm{~mm}$ wire which

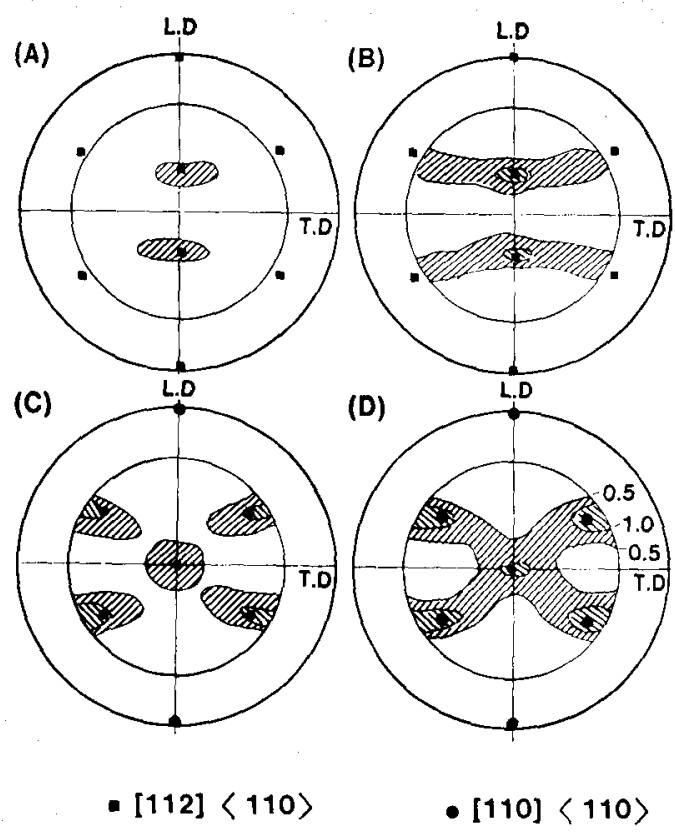

(A) Surface, conventional method

(B) Surface, new method

(C) Intermediate, conventional method

(D) Intermediate, new method

Fig. 9. (110) pole figures of the surface and intermediate layers of drawn wires patented by the conventional and new methods.

had been drawn from $12 \mathrm{~mm}$ wire rod. Texture measurement was carried out from the surface and a near surface layer (hereafter called the intermediate layer). The specimen of the intermediate layer was made from chemically polished wire. The measured layer was indicated by $d / D$, the diameter of polished wire over the diameter of the original wire.

In Fig. 9, the cylindrical textures obtained with the two patenting methods were analyzed. However, qualitatively, a difference in the tendency of the cylindrical texture formation was observed, especially in the intermediate layer. Therefore, in Fig. 10, the (200) pole figure of the specimen patented by the new method was measured to investigate the texture differences in detail. As shown in Fig. 10, the $\{112\}\langle 110\rangle$ cylindrical texture was also observed at the surface layer. However, in the intermediate layer, the $\{110\}\langle 110\rangle$ cylindrical texture and another texture which was thought to be the $\{110\}<114\rangle$ cylindrical texture were observed. But qualitatively, no difference between the new and the conventionally patented wires was detected.

Fig. 11 shows the change in microstructure observed at the intermediate layer of the above-mentioned specimen, compared with that of conventionally patented wire. Hosford previously demonstrated that the curled grain formed by drawing in the cross section of the wire is related to texture formation in view of plane strain deformation." In the case of pearlitic microstructure, the unit of curled grain corresponds with colonies. Fig. 11 shows the curled colonies. However, the degree of fragmentation of the cementite segment that occurred was different in each of the colonies. It has been shown that the 


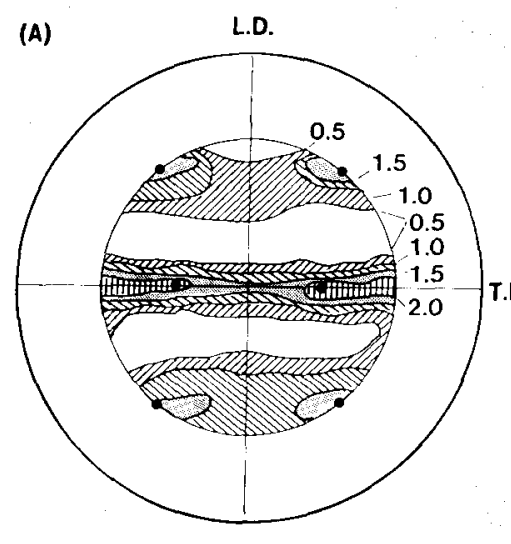

- $[112]\langle 110\rangle$

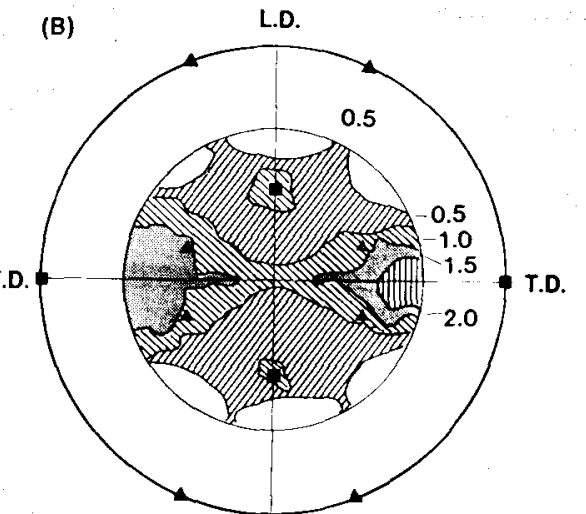

- $[110]\langle 114\rangle$

- $[110]\langle 110\rangle$
(A) Surface (B) Intermediate

Fig. 10.

(200) pole figures of surface and intermediate layers of drawn wire patented by the new method.

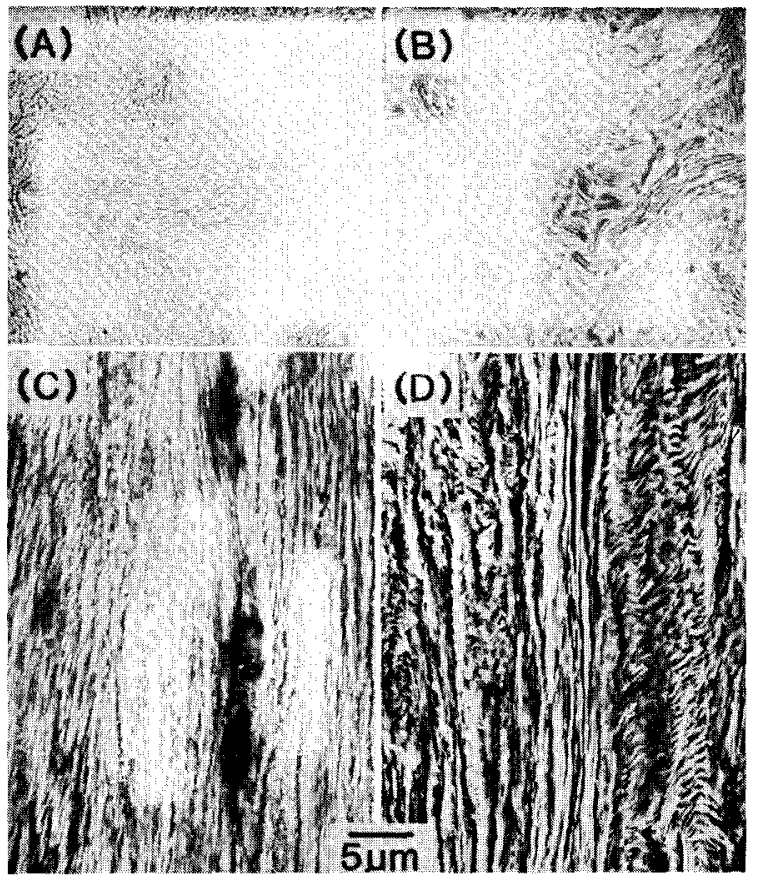

(A) Transverse section with the conventional method

(B) Transverse section with the new method

(C) Longitudinal section with the conventional method

(D) Longitudinal section with the new method

Fig. 11. Change in pearlite microstructure observed at intermediate layer after drawing.

colonies deform in two ways. One is deformation accompanied by cementite fragmentation and the other is deformation by mutual slip of each lamellar, which is called "the deck of cards" deformation. The latter case was interpreted by Langford to be intact lamellar in drawn wire.5) In the case of the wire patented by the new method, a relatively long segment was observed, which is considered to be Langford's intact lamellar formed by the deck of cards deformation.

\subsection{Texture Development of the Thick and Thin Wire Rod Patented by the Conventional Method}

The pole figure measurement showed a double cylindrical texture formation, and indicated that the

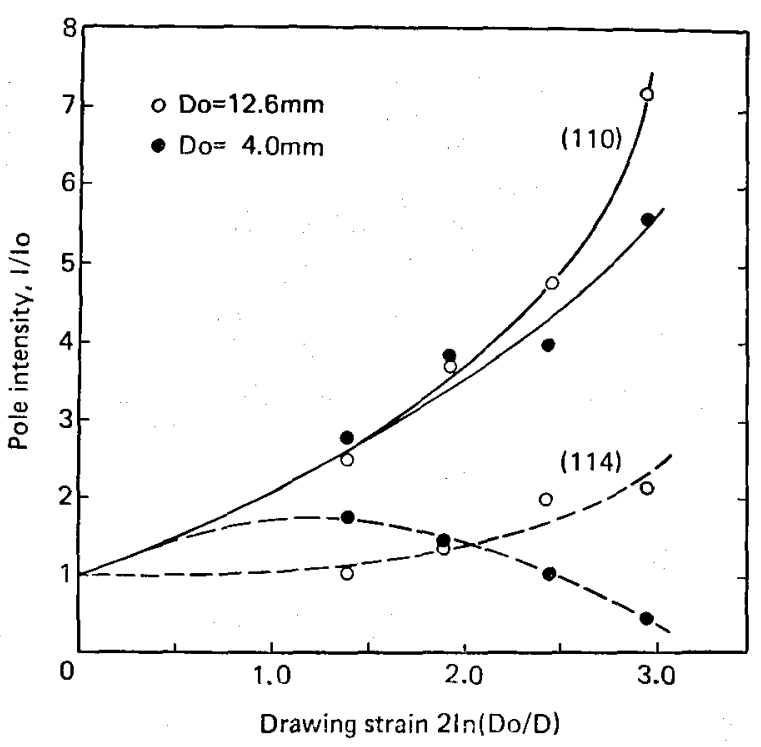

Fig. 12. Effect of the wire rod diameter on the development of the relative pole intensity of (110) and (114) by drawing.

development of the final $\{110\}\langle 110\rangle$ texture would be related to the $\{110\}\langle 114\rangle$ texture development.

In Fig. 12, the relative pole intensity of $(110)$ and (114) reflections was measured in relation to the drawing strain. The specimens were drawn from thin and thick wire rod patented by the conventional method. This figure shows that the axial $\langle 110\rangle$ and $\langle 114\rangle$ textures of the thick wire rod was developed by increasing the degree of drawing, as reported by Gubchevskii et al. $^{3)}$ in the case of low carbon steel wire. However, the axial $\langle 114\rangle$ texture of the thin wire rod increased at lower drawing strain and decreased in intensity above the drawing strain of 1.5. On the basis of the result obtained for low carbon steel by Gubchevskii et al., it was decided that the behavior of the $\{110\}\langle 114\rangle$ in pearlitic steel was affected by the lamellar structure.

\section{Discussion}

In consideration of the above results, the cause of the dependence of the wire rod diameter on delamination was attributed to the pearlitic microstructural 
change due to the mass effect during patenting.

In the previous report, ${ }^{\prime \prime}$ it was found that the $\{110\}\langle 110\rangle$ cylindrical texture development at the intermediate layer would be closely responsible for the generation of the delamination. In this study, it was observed that the $\{110\}\langle 110\rangle$ texture development was affected by changing the wire rod diameter and was related to the development of the $\{110\}\langle 114\rangle$ texture as shown in Fig. 12.

Following is the discussion about the relation of pearlitic microstructural change due to the change in transformation temperature to the $\{110\}\langle 114\rangle$ texture development and the deck of cards deformation mode observed at the intermediate layer of the wire patented by new method.

As is well known, the pearlitic microstructural change that depends on the transformation temperature, is lamellar spacing and the crystallographic property, such as the habit plane between cementite and ferrite. ${ }^{6)}$ The formcr, lamellar spacing was considered to be an important factor in an analysis of the work hardening behavior but the latter would be responsible for the deformation mode of each colony. ${ }^{7}$ The habit plane of pearlitic ferrite has been identified as the $\{112\}$ or the $\{125\}$ associated with Bagaryatskii or with the Pitsch orientation relationship. According to Schastivtsev and Yakovleva, ${ }^{8)}$ and Sakhomlin, ${ }^{9}$ ) the crystal orientation relationship of pearlite depends on the transformation temperature, and the Bagaryatskii type becomes predominant at the nose temperature. Recently, Hackney and Shiflet ${ }^{10}$ confirmed that faceting occurred in pearlite with the Bagaryatskii type by transmission electron microscopy. Therefore, it can be considered that the microstructures of the thin wire rod patented by the conventional method and the wire rod patented by the new method are the Bagaryatskii type pearlite.

On the other hand, as reported in the previous report, torsional deformation behavior, particularly delamination, was affected by the $\{110\}\langle 110\rangle$ cylindrical texture.

In this study at the intermediate layer the $\{110\}$ $\langle 114\rangle$ cylindrical texture was observed as well as the $\{110\}\langle 110\rangle$ cylindrical texture. In the case of the thick wire rods, similar result as reported in Ref. 3 ) in the case of the low carbon steel was obtain. ed. However, in the case of the thin wire rod the $\{110\}\langle 110\rangle$ texture development was reduced and the different manner of the $\{110\}\langle 114\rangle$ development occurred. This fact indicates that the Bagaryatskii type pearlite have an advantage of the $\{110\}\langle 114\rangle$ texture development.

The following is a discussion of the relation between Bagaryatskii type pearlite and the $\{110\}\langle 114\rangle$ texture. Fig. 13 shows the $(110)_{*}$ standard stereographic projection, in which the habit plane of the Bagaryatskii type is shown. In this figure, slip direction [111] lies parallel to the habit plane, and the angle between [111] slip direction and the wire axis is identical to that in the case of the $\{110\}\langle 110\rangle$ texture. This relation leads to the mutual slip of the cementite plates along the wire axis. It is expected,

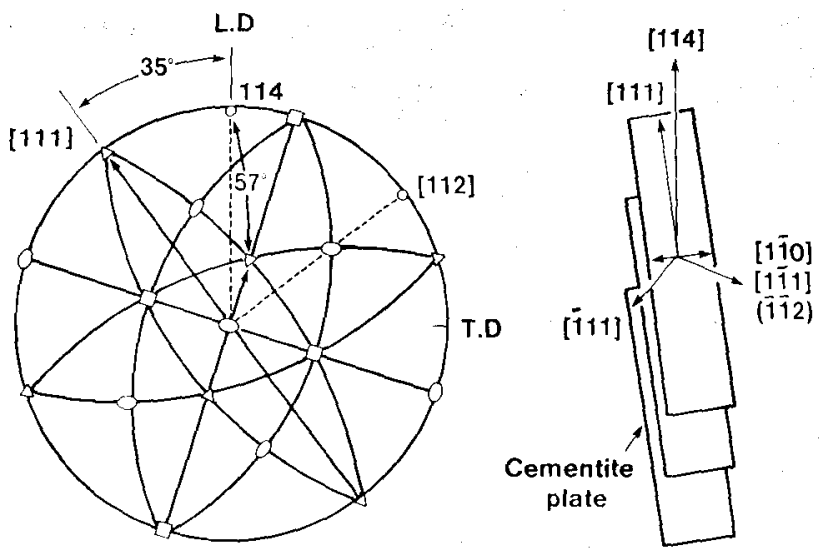

Fig. 13. (110) standard projection showing the orientation relationship among the $[110]\langle 114\rangle$ texture, the (112) habit plane of pearlitic ferrite with the $\mathrm{Ba}$ garyatskii orientation relationship, and the [111] slip directions.

therefore, that in the carly stage of drawing, the $\{110\}<114\rangle$ texture is favorable for deformation of the Bagaryatskii type pearlite along the wire axis. Furthermore, considering that the curling of the cementite segment occurred in the cross section of the wire to satisfy compatibility, the other slip directions, [III] and [11T], would operate simultaneously because they have the same orientation relation to the cementite plate. The gradual bending of cementite in the cross section of the wire would be attributed to the operation of these two slip directions. Therefore, this orientation relationship did not fragment the cementite plate unlike the Pitsch relationship. Progressive drawing would be accompanied by a gradual reduction of the $\{110\}\langle 114\rangle$ texture, and the formation of the final $\{110\}\langle 110\rangle$ cylindrical texture would be retarded.

It is hoped that a more detailed investigation of the substructural aspects of the deformation of lamellar pearlite will lead to a quantitative understanding of the relation between texture and delamination.

\section{Conclusion}

Delamination was studied by the new patenting method involving the application of high pressure. A comparison of the resulting mechanical properties and the texture development indicated that delamination is controlled by $\{110\}\langle 114\rangle$ texture formation and the crystallographic property of pearlite. This behavior has been explained by the Bagaryatskii type pearlite which has been observed frequently at a lower transformation temperature.

\section{Acknowledgements}

The authors wish to thank Dr. Yoshiro Yagi of KOBELCO Research Institute, Inc. and Dr. Toru Araki of Kobe Steel, Ltd. for their suggestions and encouragement.

\section{REFERENCES}

1) Y. Kanetsuki and R. Ogawa: Proc. 6th Int. Conf. Tex- 
tures of Materials, II, Iron Steel Inst. Japan, Tokyo, (1981), 1127.

2) T. G. Nilan: Trans. AIME, 239 (1967), 898.

3) V. P. Gubchevskii, V. A. Zemlyanskov, D. M. Zlatoustovskii, L. D. Zlatoustovskaya and E. D. Nemkina: Steel in USSR, 5 (1975), 276.

4) W. F. Hosford, Jr.: Trans. AIME, 230 (1964), 12.

5) G. Langford: Met. Trans., 1 (1970), 465.

6) Y. Ohmori, A. T. Davenport and R.W.K. Honeycombe:
Trans Iron Steel Inst. Jpn., 12 (1972), 128.

7) J. Gil Sevillano, P. Van Houtte and E. Aernoudt: Proc. 5th Int. Conf. "Texture of Materials", II, G. Gottstein and K. Lücke, ed., Springer-Verlag, Berlin, (1978), 495.

8) V. M. Schastlivtsev and I. L. Yakovleva: Phys. Metal and Metallogr., 38 (1974), 109.

9) G. D. Sukhomliln: Phys. Metal Metallogr., 38 (1974), 192.

10) S. A. Hackney and G.J. Shiflet: Scr. metall., 19 (1985), 757. 